\title{
NPD, Design and Management for SME's.
}

\author{
FORD, Peter* and TERRIS, David \\ Affiliation Organisation, De Montfort University, Leicester, UK \\ * Corresponding author e-mail: pbford@dmu.ac.uk \\ doi: 163
}

It is generally acknowledged that small and medium sized enterprises (SME's) contribute significantly to a country's economic performance. It is also generally acknowledged that it can be problematic to provide effective, public sector research, development and innovation support for SME's given their size and diversity. It is also considered that vertical cooperation with customers and suppliers is more effective in new product development (NPD) for SME's than horizontal co-operation with research institutions and government agencies. This paper discusses how higher education institutions (HEI's) engaged in design research, can effectively support SME's in NPD by actively participating in the design process whilst simultaneously working with SME's to facilitate the development of knowledge networks local to specific SME's, by acting as an intermediary. A number of design support schemes and specific SME, NPD projects undertaken by the author are used to advocate a participatory intermediation role for $\mathrm{HEI}^{\prime} \mathrm{s}$ in supporting NPD for SME's.

keywords: SME's; NPD; HEI; participatory

\section{Introduction}

Chiva and Alegre state:

Companies that manage design effectively and efficiently attain better performance than those that do not. Therefore, good design does not emerge by chance or by simply by investing in design but rather as a result of a managed process. (Chiva \& Alegre, 2009, p. 424) 
This statement is applicable to both large enterprises (LE's) and SME's alike, however it is generally acknowledges that where an SME is not of a size whereby it can readily invest in design or a design management capability, that they are likely to be at a disadvantage in the early stages of the NPD process (Ford, 2016).

It is generally accepted that with increased availability and mobility of knowledge workers and increased access to a vast array of external suppliers via internet sources etc., that traditional innovation systems have been undermined and that innovation is taking place more and more outside of a single firm (Chesbrough, 2003).

In spite of increasing interest in open innovation networks, most studies on its effects have been centred on LE's (Lee et al., 2010), indeed discussions on open innovation in SME's appear to have been excluded from mainstream research (West et al., 2006). Simply open innovation can be more readily observed in LE's as SME's generally have a lesser ability to access external resource and have fewer technological assets to exchange than larger firms (Narula, 2004); for the LE this would be considered vertically integrated, operating from 'a comforting, landscape of abundant knowledge' as Chesbrough refers to it (2003 p. XXV).

However in the current, fast changing global market, SME's exert a strong influence on the economy of many countries (Zeng et al., 2010); the ability for SME's to innovate and develop new products and processes are a primary source for economic growth and technological progress (Bruque and Moyano, 2007).

In the UK alone, figures show that (including sole traders) SME's account for $99 \%$ of business, $55 \%$ of non-governmental employment and $51 \%$ of turnover (SBS, 2001). In 2015 , this was estimated at a gross value of $f 1.754$ billion (Rhodes, 2015), the manufacturing element accounting for $£ 280$ billion (Rhodes, 2015).

The innovation agenda for SME's cannot therefore be ignored, however there appears to have been very few studies of innovation models that are specialised for SME's (Lee et al,. 2010), particularly as there is evidence of tremendous growth in the use of external networks by firms of all sizes (Hagedoorn, 2002).

In keeping with Chiva and Alegre's comment on the benefits of effective design management in NPD, Hewitt-Dundas (2006) makes the observation that where SME's have access to and seek external innovation partnerships in order to stimulate capacity for innovation, the results are positive in terms of NPD, and that a lack of innovative partnerships actually had a negative impact on innovation. Cumbers et al., (2003) identify that there are advantages to be gained from localised networks which are of particular importance to SME's when offsetting the size-related advantages of larger firms. The impact of innovation networks on SME's cannot therefore be ignored; indeed it would appear that the nature of innovation networks is critical in fostering innovation. For example it has been noted, where relationships with customers, suppliers, service providers, etc., are vertically orientated, the results of these collaborations appear to yield a greater level of innovative output when compared to competitors who do not collaborate externally (Cooke et al., 2000; Kaufman and Todtling, 1999; Diez, 2002; Doloreux, 2004), very much in keeping with Chesbrough's thinking on open innovation. In 2002 Fischer and Varga undertook a postal survey producing data on innovation and inter-firm relationships and found that networking activities with these SME's were indeed 
primarily based on vertical relationships (customer, supplier and producer service provider networks) rather than on horizontal linkages (producer networks, industry-university linkages).

The nature of such networks is pivotal in how SME's operate; external collaborations being more likely and required, in order to bring about innovation (given an SME's size). As Bruno Latour describes in his discussions on Actor-Network Theory (ANT), these networks go far beyond a technical meaning, indeed he states:

An actor-network may lack all the characteristics of a technical network - it may be local, it may have no compulsory paths, no strategically positioned nodes. (Latour, 1996, p. 369)

In Latour's terms these networks are complex, actors within these networks extending to the non-human and the non-individual (Latour, 1996); as Law describes (2009), these networks embrace both the material and the semiotic. This cannot be divorced from design and the NPD process, indeed Albena Yaneva (2009) effectively relates such actornetworks to the design of products and environments. So does this have implications on NPD for SME's and the actors within the sphere of their activity (including designers) and the management of this by them or those acting on their behalf?

Pekkarinen and Harmaakorpi (2006) note the often heterogeneous nature of innovation networks which may include actors from universities' technology centres and development organisations, indeed Bulinger et al. (2004) and Becker and Dietz (2004) suggest that collaborations between universities, researcher institutes, suppliers and customers had a positive effect on innovation and the development of new knowledge. However there is some evidence that firms, including SME's, are rarely interacting with universities and contract research organisations (Cooke et al., 2000).

\section{Vertical or Horizontal}

There appears to be a dynamic here between vertical and or horizontal innovation networks and the relationship with a variety of actors and SME's and in particular what would appear to be horizontal relationships with HEl's.

Zeng et al., (2010) make a compelling argument when they compare the findings of Cooke et al. (2000), Whitley (2002), Doloreux (2004) and Nieto and Santamaria (2007) and identify that there are significant differences in impact based on different types of network accessed by innovation firms. They make the point that vertical cooperation/collaboration with customers, suppliers, producers, etc., plays a more distinct role in innovation for SME's than horizontal with cooperation with $\mathrm{HEI}$ 's, research institutes and government agencies, indeed they suggest that the significance of cooperation with research institutes, HEl's and intermediaries with supporting SME's innovation is less than could be expected.

So, where does this place HEl's in terms of supporting SME's and in particular HEl's that undertake design research, and would collaborations in this context be deemed vertical or horizontal?

It is generally understood that research organisations, HEl's and Technological Institutes have not traditionally focussed on filling out the innovation processes of firms but on providing them with new knowledge including the scientific and the technical (Lundvall. 1992; Drejer and Jørgensen, 2005). In this context relationships with industry might be described as being horizontal, that is being an organisation that on its own volition 
generates new knowledge which in turn may or may not become of commercial value to an external party. It would appear however that this has changed in recent years with Governments encouraging institutions, including HEl's, to undertake research directed at boosting the competitiveness of industry (Tether et al., 2002), but would this be considered as vertical or just another form of horizontal with a different emphasis; that is, independent research inspired by industry needs rather than just independent research? Simply, if such research, whatever the inspiration, is undertaken as a specific element of a project only and undertaken in isolation from other factors relating to the project as a whole, then this may be considered as horizontal. In terms of NPD, a vertical relationship would involve collaboration with clients, suppliers, producers and end users etc., necessitating a more holistic relationship with all concerned in the development of a product. As Miotti and Sachwald (2003) define, such vertical relationships have a more significant impact on both product and process innovation.

Design requires the understanding of a wide range of criteria in order to determine the best balance of compromise in effective NPD (Design being the art of minimising compromise); therefore, generally speaking, design research in the context of NPD necessitates a broad understanding of all the criteria pertinent to the development of a product which is inherently a vertical activity, which in turn raises an interesting question regarding the place and role of design research from an $\mathrm{HEI}$ perspective.

As Lee et al., (2010) suggest, open innovation occurs at all stages of a product's lifecycle, from technological exploration through to full commercialisation. There would therefore appear to be a close correlation between the scope and role for design in NPD and scope for open innovation for SME's within vertical relationships.

\section{Intermediary or Broker}

A considerable amount of literature has been produced relating to innovation and the roles of intermediaries in the NPD process. It was realised early on that 'change agents' could exert a powerful influence on the speed of knowledge diffusion and the uptake of new products (Hägerstrand, 1952; Rogers, 1962). As has been discussed, these dynamics are more easy to observe in the large vertically orientated companies than with SME's, but given the certainty that an 'open' approach to innovation with SME's is beneficial (Zeng et al., 2010), governments have carried out policy initiatives to promote innovation of the small firms sector as a source of radical innovation (Hewitt-Dundas, 2006), indeed a number of policy makers have been established to directly or indirectly assist SME's undertake product process innovations (Smallbone et al., 2003). But government support hasn't always been successful, in particular with regard to design support initiatives.

A UK, Department of Trade and Industry (DTI) report on a Government design support scheme in operation in the mid -80 's (the Funded Consultancy Scheme) came to the conclusion that this initiative had fallen short of the Design Council's (the Government sponsored funding body) central objective - to ensure that design became 'an integral part of corporate strategy and incorporated at all stages of product development' (DTI Assessment Unit, 1988, para. 9). Later the researchers Roy and Potter were also critical that only a quarter of the 5000 funded projects remained unexecuted or ended with disappointing commercial results (Roy \& Potter 1990). Ford and Woudhuysen (2015) made the following observations: 


\begin{abstract}
With manufacturer SMEs, then, publicly funded initiatives that include product design long ago met problems in embedding design, the communications that surround the design process, and the managing of design. So while the state can act as a broker of and a funder for the direct practice of design, introducing manufacturer SMEs to design consultants and paying for at least some of their work, these functions alone don't guarantee success in NPD - and, still less, the absorption of design into a manufacturer SME's overall culture. (Ford and Woudhuysen, 2015, p. 66)
\end{abstract}

So it can be seen that the role of the intermediary and the broker is complicated with potential to be successful and less than successful; nevertheless research suggests that open innovation is of considerable value to SME's and that intermediated networks can be an effective model in aiding collaboration (Lee et al., (2010) and therefore innovation.

Hargadon and Sutton (1997) from their study of the consultancy IDEO stress that brokering is more than just a linking role, but helps transform the ideas and knowledge being transferred, that it can be active in the process, even generating new knowledge. Indeed this hails back to the works of Nonaka and Takeuchi (1995) and the interplay of both tacit knowledge, held by individuals, and formal, explicit knowledge. In particular when there is interplay between the tacit and the explicit and vice versa, firms can benefit from this 'knowledge spiral' and acquire 'organisational' knowledge; therefore when carefully managed, this process can embed new knowledge within and SME (Ford, Wouydhuysen. 2012), leaving a legacy. Howells (2006) makes the point that:

Intermediaries are, therefore, not only providing immediate, 'one-off' intermediary services to their clients, but are also seeking to offer longer term, 'relational' innovation capabilities to them as well', and that "these collaborations can last for periods of years, not months. (Howells, 2006, p. 724)

Indeed Howell's study suggests that intermediaries can provide a much more varied and holistic role for clients in the innovation process than has generally been acknowledged and actually "create new possibilities and within a system.

Howells also makes the observation that intermediaries often remain specialised around a specific activity but that the range of services and expertise expands over time. This notion of time affecting intermediary SME relationships is important as it implies the need for a more intimate role between intermediary, broker and SME.

Nieto and Santamaria (2007), referring to Hoecht and Trott (2006) state the innovation capacity of a firm is largely dependent on cumulative knowledge built up over many years of experience, and that Powell et al. (1996) state that network experience should be considered as an incremental learning process in two ways, firstly in terms of the technical learning of innovations and secondly, in terms of the management of collaborations. Cohen and Levinthal (1990) use the term "absorptive capacity" in a process orientated context, to determine how fit a company is to innovate, suggesting that this ability is increased where there has been prior experience of the innovation process. Levitt and March (1988) make the observation that firms repeatedly engaged in an activity learn from these experiences and in so doing accumulate knowledge. As Nieto and Santamaria state: 
All of the above leads us to argue that firms with experience of collaboration acquired through long-standing relationships are likely to enjoy better alliances, which in turn could have positive implications for innovation outputs. (Nieto and Santamaria, 2007, p. 369)

\section{In Summary}

To summarise, an argument has been made for the need for SME's to engage in open innovation, possibly through knowledge networks (including those relating to ANT), possibly with the assistance of intermediaries, in order to gain market advantage. Indications are that vertical relationships with suppliers, sub-contractors, clients and end users are likely to be more effective in NPD for SME's than just a horizontal relationship with research organisations and HEl's undertaking technology based and similar research. The notion that design thinking and the design process can be readily aligned to a vertical approach to NPD and that the role of an intermediary, who is actively engaged in the process (not just facilitating links), can help an SME absorb and accumulate knowledge, either through direct influence or the through establishing and managing knowledge (organisational knowledge) networks, has been discussed.

The issue of time has also been discussed and the merits of long term relationships in the building of knowledge and to provide time for the embedding of that knowledge. The question has been asked, where does this place HEl's in terms of supporting SME's and in particular HEl's that undertake design research, and would collaborations in this context be deemed vertical or horizontal? In this context, this paper presents the work of the Design Unit (RG), a design research group, operating out of De Montfort University (Leicester, UK) as an example of how:

- Vertically orientated design research and innovation can be embedded into the NPD strategies of SME's

- An intermediary can act as an effective knowledge broker in the NPD cycle and in the management of knowledge networks and also play various 'actors roles' within the process

- Embed organisational knowledge within an SME as a lasting legacy of the NPD process

- Time is significant in relationships with SME's

The findings in this paper are therefore observational, based on a number of Design Unit (RG) projects undertaken in recent years and in particular observations on the relationships with related actors and networks. In particular this has afforded an opportunity to observe interplay of both actively designing in and actively managing the design process; what might be considered a Design or Design Management relationship with SME's.

The author of this paper therefore acknowledges a close relationship to the findings, but nevertheless hopes that these observations make for valid insights.

Briefly, in the next section, the paper will consider: 
- The nature of the Design Unit (RG)

- The RG developed knowledge networks

- Short case studies illustrating network links

- Impact

\section{The Design Unit (RG)}

RG is a design research group now in its $25^{\text {th }}$ year which has undertaken a wide variety of design research projects for SME's, large enterprises (LE's), local government and other research bodies. RG is therefore in a position to undertake and perform design innovation, manage projects and forming a research perspective, reflect on these undertakings.

Projects have ranged considerably in scope but generally about $80 \%$ (either directly or indirectly) of RG's activity revolves around product design research interventions for private sector SME's and LE's. In recent years RG has seen significant growth activity funded by research councils

Prior to 2004 RG had responded solely to private sector inquiries, briefs and specifications being supplied by these companies (owners, directors, project managers etc.). Generally speaking RG was being used as a conventional design consultancy or consultants in design research and forecasting. In essence and by default RG was operating as a collaborator within a vertical structure of NPD on behalf of the SME's and LE's they collaborate with. From 2004 to 2012 RG managed to lever funding from regional development agencies (RDA's) to design, establish and run regional, design support schemes (see Ford, Woudhuysen, 2012 for more detail), briefly, these are described as follows:

\section{Scheme 1}

Funded by the East Midland Development Agency (EMDA), Scheme 1 ran from 2003 until 2007. 180 companies were approached, 52 possible projects were identified and 16 were subsequently funded. RG did not undertake any product development tasks themselves but manged the projects, devised project briefs (with the client companies) and identified/sourced other collaborators into the individual teams and vertical NPD structures.

Overall 8 product design agencies, 2 engineering groups, 2 electronics developers, 2 prototyping houses and 2 trade plastic moulders were enlisted into the schemes and allocated to specific projects.

Generally speaking the core design stages of each project were fully funded by EMDA and all projects were developed from concept through to manufacture resulting in 12 products making it through to manufacture. Project durations were mixed ranging from 18 months to 6 years in two instances.

\section{Scheme 2}

Funded by the Manufacturing Advisory Service (MAS), Scheme 2 ran from 2008 until 2009. 65 companies were approached, 13 were subsequently funded. In this case RG undertook 6 of the projects with other actors being assigned to the remaining projects. Again RG manged the projects, devised project briefs (with the client companies) and identified/sourced other collaborators into the individual teams and vertical NPD structures. 
Overall 5 product design agencies (4 the same as with scheme 1 and 1 new agency), 1 engineering group, 2 prototyping houses (same as for scheme 1 ) and 1 (different to the 2 in scheme 1) electronics developer were enlisted into the schemes and allocated to specific projects. In addition 2 government funded regional innovation support agencies, 1 intellectual property group, 1 trade plastics moulder (different to scheme 1 ) and 1 trade toolmaker were co-opted into the scheme.

On this scheme the core design stages of each project were $50 \%$ funded by the MAS and again all projects were developed from concept through to manufacture resulting in 11 products making it through to manufacture. Project durations were again mixed ranging from 18 months to 4 years.

\section{Scheme 3}

Funded by the European Regional Development Fund (ERDF), Scheme 3 ran from 2009 until 2012. 110 companies were approached and funded to varying degrees. In this case RG undertook about $60 \%$ of the projects with other actors being assigned to the remaining projects. RG once more managed the projects, devised project briefs (with the client companies) and identified/sourced other collaborators into the individual teams and vertical NPD structures.

Overall 6 product design agencies ( 2 being different from schemes 1 and 2), 1 engineering group and 1 electronics developer (not additional to schemes 1 and 2), 3 prototyping houses ( 2 the same as for schemes 1 and 2 and 1 additional) were enlisted into the schemes and allocated to specific projects. In addition 2 government funded regional innovation support agencies (the same as scheme 2), 1 intellectual property group, 1 trade plastics moulder and 1 trade toolmaker were co-opted into the scheme (the same as for schemes 1 and 2).

On this scheme the core design stages of each project were fully funded by ERDF, but generally $65 \%$ of the projects were given a modest level of support with the remaining $35 \%$ being developed once more from concept through to manufacture, resulting in about 50 products making it through to manufacture in one form or another (the majority being from the 35\%). Once again project durations were mixed ranging from 1 to 3 years.

\section{The RG Development of Knowledge Networks}

Overall, these schemes represent a substantial amount of design activity over a 9 year period; 140 projects with a significant number making it through to manufacture. A general observation is that that project supports of this type can result in protracted project lead times for SME's.

"A deduction from this is that SME's quite simply need more time and consistent $M / I$ support (the 'heavyweight manager') throughout these, often protracted periods, to achieve a successful outcomes in NPD" (Ford, 2016, p. 10)

It is also interesting to note the number of players engaged in this period, (note, the actors listed in schemes 1 to 3 are the primary participants, in reality there were also a considerable number of minor players) these are as follows:

- Product design consultants

- Engineering consultants 
- Electronics developers 2

- Trade moulder 2

- Trade toolmaker 1

- Government innovation support bodies 2

- Intellectual property specialists 2

- Prototyping agencies 3

The common denominator in these relationship's though is RG, not only is it performing an intermediation role (Lee et al., 2010), but is actively participating in undertaking specific tasks in the NPD process (Howells, 2006).

\section{Short Case Studies}

To demonstrate the dynamic of these knowledge networks further, this section presents four short case studies relating to specific projects/client relationships RG have undertaken/engaged with in the past 5 years. In particular they will attempt to define (simply) the network of key players in each project scenario over a period of time. Finally these networks will be overlaid one against the other to illustrate the dynamic between projects. Figure 1 provides a key to the actors in the case studies.

Research Group

Figure 1 Key to Actors in the Case Studies

\section{Case Study 1 - Medical Device Company (MDC)}

MDC was founded in 2004 when they set out to become a distributer of medical technology for critical care, operating theatres and other applications.

As this brought MDC into close proximity to clinical services, they were able to identify when leading clinicians had ideas and developments for new products in their infancy and could see opportunities for NPD from which they could generate their own products resulting from these collaborations.

Their first venture into NPD was the development of a Xenon re- breathing circuit, a product that manages the delivery of Xenon gas and the removal of $\mathrm{CO} 2$ to and from extremely premature babies to help minimise the risk of potential brain damage.

RG was recommended to MDC for design assistance by a government run medical device support group (MDS) in 2011; the project being to design and develop this circuit in consultation with MDC's clinicians. RG worked with MDC to produce a patented design (P1) concept and 200 prototypes using a rapid prototyping (RP).

Electronics systems used in the monitoring of Xenon, $\mathrm{O} 2$ and $\mathrm{CO} 2$ in the system was also critical in the development; RG was able to direct MDC to an appropriate electronics collaborator (EC). Within 18 months the prototypes were on clinical trial, the results of which have been very encouraging to date; trials are still ongoing. 
Based on this success, in 2013 MDC established its own in-house design team (MDC-IH) product development and regulatory activities have subsequently, largely been developed by this team including their own neonate nCPAP device (to help premature babies on a ventilator). Following the development of the infant Xenon re-breathing circuit; MDC have continued to involve the RG with the development of an adult Xenon re breathing unit securing a substantial Small Business Research Innovation grant to achieve this (Grant 1). MDC have subsequently 'floated' on the stock market and entered into a joint venture to develop the adult Xenon device with a USA based investment group (IG). See figure 2.

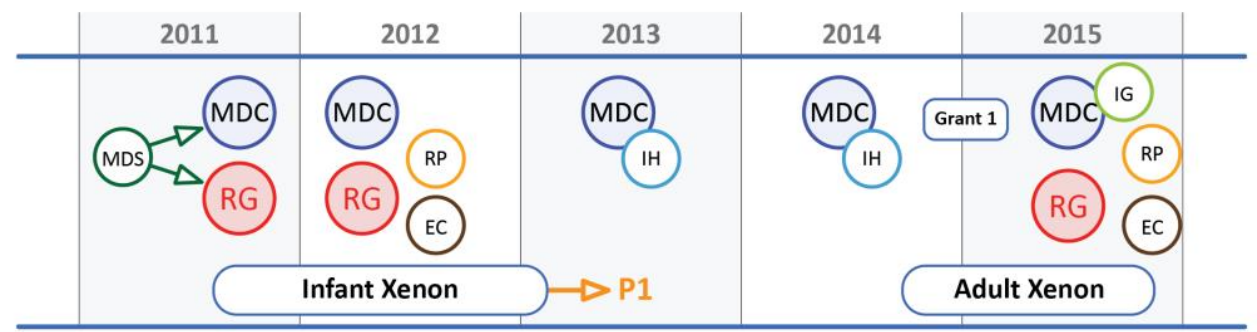

Figure 2 Case Study 1 -Actors/Knowledge Network. Source: The Author

\section{Case Study 2 - Retail Display System (RDS)}

RDC are a 90 person SME who manufacture for the retail display industry, their clients include Wickes, Chanel, Lancome etc., essentially they manufacture check-out desks and concession displays. The retail display industry faces fast product turnarounds with stores being refitted every 18 months to 2 years. As most of the materials used in the construction of these products are based on painted or laminated medium density fiber board (MDF), the majority of these materials will find their way into landfill at end of life - the paint and bonded laminate fundamentally contaminating the base material.

These materials are also heavy, making for a significant tonnage of material going into landfill on an annual basis. This project was therefore to develop a light weight construction approach for retail display systems that does not require painting or laminating of substrate materials.

RDC were introduced to RG through the scheme 3 Europe funded design support project being managed by RG. This scheme funded initial concept work leading to a patent (P2) application (granted in 2015) for a novel, method of retail display construction (based on a tensioning system) that was indeed light, strong and did not require significant bonding and painting. Innovate UK funding was obtained (Grant 2) to develop the product further to full sized working prototypes for evaluation by Wickes and Chanel. A rapid prototyping house (RP) was used to produce a number of components for the prototype. Tooling company (T1) and plastics moulding company (M1) were used to manufacture injection moulded sets of the tensioning system.

To determine the carbon footprint of the new system, collaboration was developed with specialists in life cycle analysis (LCA). The system is currently undergoing functional testing with Chanel and Wickes. See figure 3. 


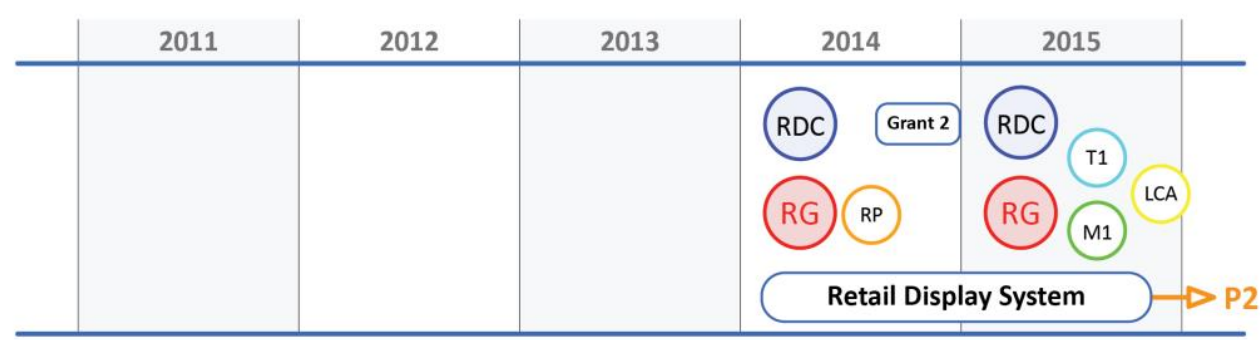

Figure 3 Case Study 2 -Actors/Knowledge Network. Source: The Author

\section{Case Study 3 - Using 100\% Recycled Plastic in Digital Phones (DP)}

DP is a large UK based multinational operator of telecommunication networks. As part of their corporate sustainability initiatives DP needed to determine how to design and manufacture plastic products from the outset when having to use $100 \%$ recycled material.

DP approached RG to determine these parameters based on actually designing and then injection moudling a prototype for a new digital phone design. Initial investigation revealed opportunities for sustainability gains beyond just using $100 \%$ recycled material this required developing semi-working electronics to incorporate within the mouldings. This necessitated collaboration with an electronics collaborator (EC), in addition to collaborations with toolmaker (T1) and plastics moulder (M1).

A number of working prototypes were produced which were subsequently destruction tested at testing house (TE1) and then environmentally (rapid ageing) evaluated at testing house (TE2). Again, as with case study 2 , a life cycle analysis of the new design proposal was undertaken by LCA. See figure 4.

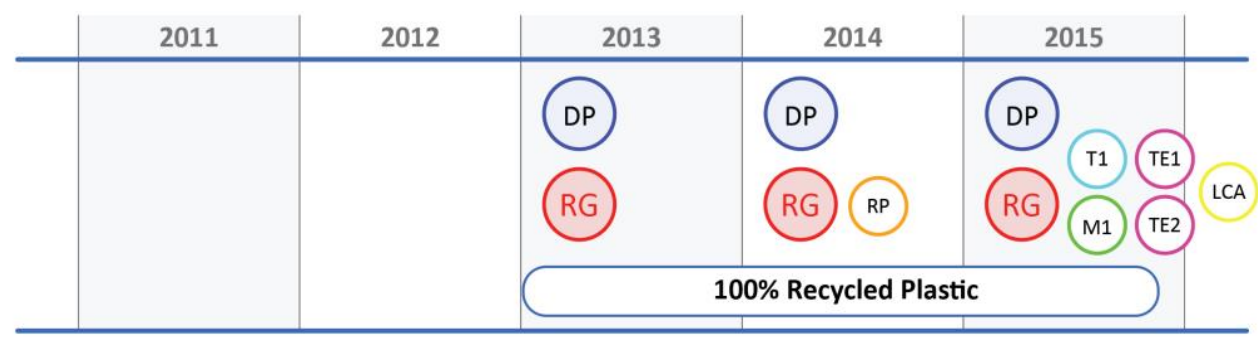

Figure 4 Case Study 3-Actors/Knowledge Network. Source: The Author

\section{Case Study 4 - Air Redistribution Medical Bed (AMB)}

$\mathrm{AMB}$ manufacture air redistribution mattresses that help prevent the occurrence of pressure sores for patients who, due to illness, are confined to bed for long periods of time. These mattresses are controlled by a bed side mounted compressor linked to a manifold and valve system that sequentially inflate and deflate to create undulations under the patient. AMB have been manufacturing these systems for a while, but generally the casework designs for the compressor and manifold are old and very expensive to manufacture. In addition the need to replace these caseworks with more cost effective solutions, there was also a requirement to innovate a new CPR coupling that could easily deflate the mattress in the unfortunate event of heart attack.

AMB was introduced to RG by the medical device support network (MDS) as part of RG's scheme 3 design support initiative. This resulted in RG undertaking a modest amount of concept 
design work for $\mathrm{AMB}$ under that scheme. During this time it became clear that the entire range of mattress compressor manifold systems and CPR valves needed re designing, this was a significant amount of work; it was also clear that AMB's managing director was too thinly stretched to have the time to project mange these new designs.

Ultimately this led to a body of design research support beyond the scope of scheme 3. AMB managed to obtain a substantial Regional Growth Fund (RGF) grant for this activity (Grant 3). In addition a 2 year Innovate UK, Knowledge Transfer Partnership (KTP) (Grant 4) to develop and embed a design and NPD resource within AMB.

Full design, prototype and production development was undertaken for a number of compressor/manifold cases and patented (P3) CPR valve systems requiring collaborations with two plastic moulding companies ( $\mathrm{M} 1$ and $\mathrm{M} 2$ ) and toolmaking companies (T1 and T2) in addition to collaborating with an electronics collaborator (EC). See figure 5.

The KTP associate (KA) has now been fully employed at AMB and is working on the next generation of products.

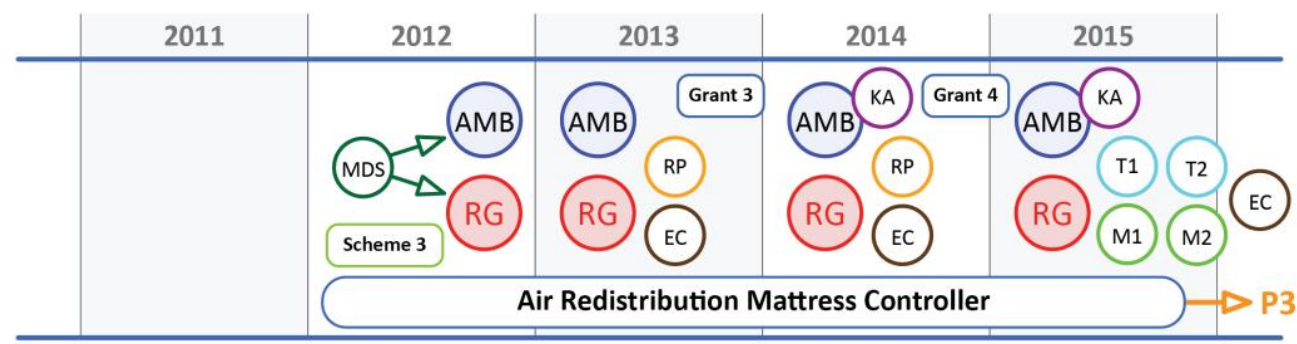

Figure 5 Case Study 4-Actors/Knowledge Network. Source: The Author

\section{In Combination}

Figure 6 combines figures 2 to 5 (although simple) to highlight/map the influence of RG on all four projects over the four year period, again proving to be a common denominator, being both an active contributor and an intermediary between actors. 


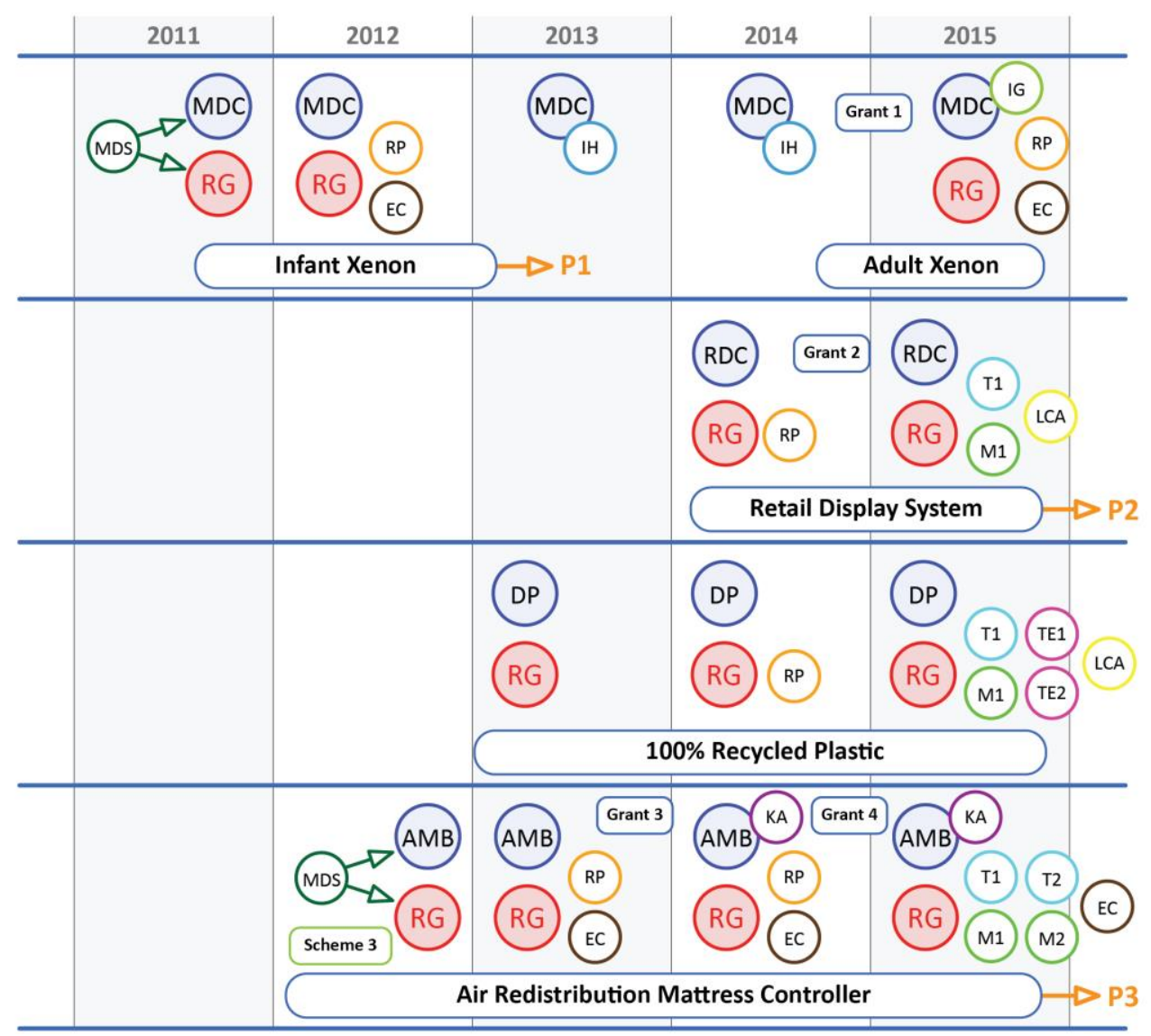

Figure 6 Spread of Actors/Knowledge Networks Over Time for the Four Projects. Source: The Author

\section{Evidence for Impact}

As implied in the RG section, the style of this method of intervention would appear to be highly successful with a $75-80 \%$ success rate of products finding their way through to manufacture (Ford, 2016). In 2005 Lord Sainsbury commended RG's scheme 1 project for achieving a 14:1 return on public sector investment (Sainsbury, 2005) through the development of new markets for UK design and manufacturing companies. In addition, following a 2014 Research Excellence Framework (REF) review of HEl's research outputs including impact case studies, the Design Unit's Design Supporting Business case study was considered as making an outstanding impact on SME's in the Region, generating millions of pounds of increased revenue in addition to job creation (DMU Research Repository, 2014).

\section{Observations and Conclusions}

It can be seen from these case studies that a design research group such as RG can assist SME's in being effective in NPD by acting and influencing at a number of different levels and by exerting this influence over substantial periods of time. In these cases, RG has not only played the role of the design and development actor, leading to the generation of intellectual property and commercially viable products, but has assisted SME's in 
establishing effective project briefs, developed networks (and actors) that overlap across a range of projects and worked with SME's to manage the design and NPD process effectively.

Figure 7 illustrates how a group such as RG can place itself vertically in the NPD process working with the SME and their knowledge/supplier networks, generating IP and new knowledge in the process, as opposed to generating IP on the periphery (a horizontal relationship); this form of support being both of active participation in the process and with intermediation between actors across the process.

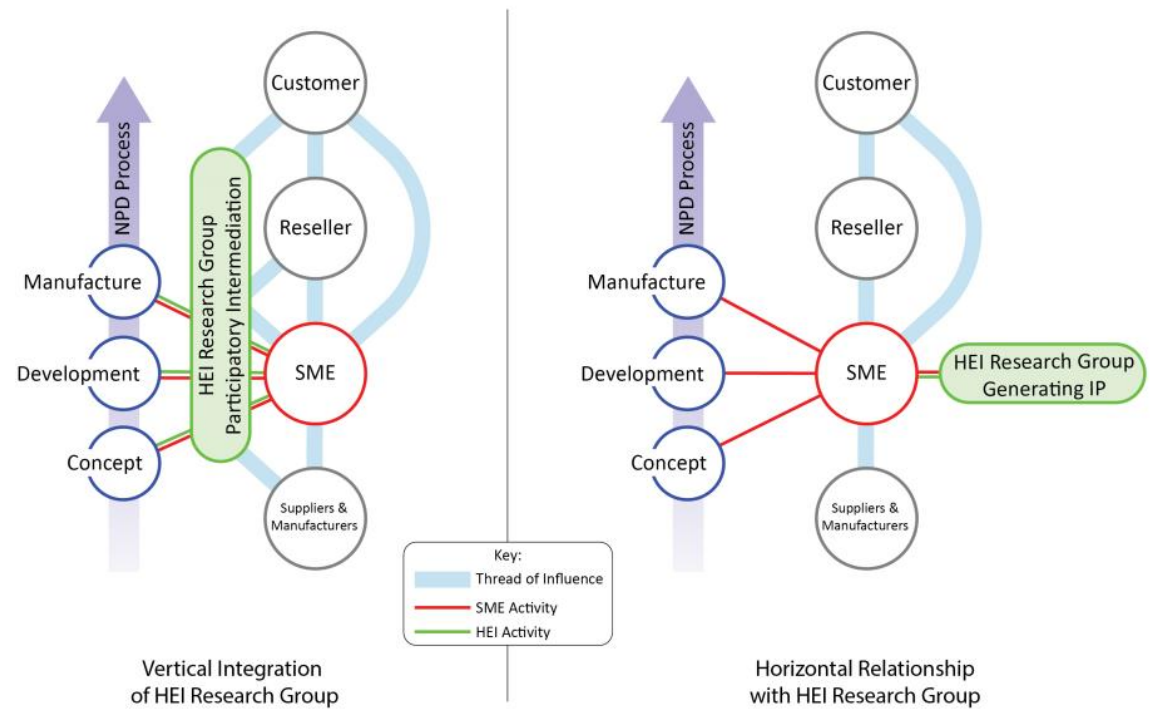

Figure 7 Vertical and horizontal HEI-SME relationships. Source: The Author

We can see here that over a period of time (Hoecht and Trott, 2006; Powell et al., 1996) a wide ranging (Chesbrough, 2003), heterogeneous group (Zeng et al., 2010; Pekkarinen and Harmaakorpi. 2006) of actors has been repeatedly engaged (Nieto and Santamaria, 2007) in a series of related, local (Zeng et al., 2010) knowledge networks. The common denominator in all these relationships is RG, performing this intermediation role (Lee et al., 2010), and undertaking specific tasks in the NPD process (Howells, 2006). Operating out of an $\mathrm{HEl}$, a group such as RG can be well placed to fulfil these roles over these periods of time and is in a position to engage in actor-networks effectively, not necessarily managing them (counter to ANT) but establishing threads of influence through them (see figure 7) to the mutual benefit of all the actors engaged. In these cases RG has had the opportunity to make tacit knowledge explicit to the SME's involved, providing confidence to invest in their own design provision thus the embedding of organisational knowledge. Being able to simultaneously provide both design and design management expertise, a group such as RG can find itself in a unique position while working with an SME, to balance the multitude criteria and actors in the NPD process making for successful outcomes at a number of different levels. 


\section{References}

Becker, W., \& Dietz, J. (2004). R\&D co-operation and innovation activities of firms: Evidence for the German manufacturing industry. Research Policy, 33(2), 209-223.

Bruque, S., \& Moyano, J. (2007). Organizational determinants of information technology adoption and implementation in SMEs: The case of family and cooperative firms. Technovation, 27(5), 241253.

Bullinger, H., Auernhammer, K., \& Gomeringer, A. (2004). Managing innovation networks in the knowledge-driven economy. International Journal of Production Research, 42(17), 3337-3353.

Chesbrough, H. (2003). Open innovation: The new imperative for creating and profiting from technology. Harvard University Press, Cambridge, MA

Chiva, R. \& Alegre, J. (2009). Investment in design and firm performance: The mediating role of design management. The Journal of Product Innovation Management, 26, 424-440

Cohen, W.M., \& Levinthal, D.A. (1990). Absorptive capacity: a new perspective of learning and innovation. Administrative Science Quarterly 35(1), 128-152.

Cooke, P., Boekholt,P.,\& Tödtling , F. (2000). The Governance of innovation in Europe: Regional perspectives on global competitiveness. Pinter London and New York.

Cumbers, A., Mackinnon, D., \& Chapman, K. (2003). Innovation, collaboration, and learning in regional clusters: A study of SMEs in the Aberdeen oil complex. Environment and Planning, 35(9), 1689-1706.

Diez, J.D. (2002). Metropolitan innovation systems: A comparison between Barcelona, Stockholm, and Vienna. International Regional Science Review, 25 (1), 63-85.

Doloreux, D. (2004). Regional networks of small and medium sized enterprises: Evidence from the metropolitan area of Ottawa in Canada. European Planning Studies, 12(2), 173-189.

Drejer, I.,\& Jørgensen, B.H. (2005). The dynamic creation of knowledge: Analysing public-private collaborations. Technovation, 25, 83-94.

Department of Trade and Industry Assessment Unit. (1988). Support for Design Summary and Conclusions. AU Report No 3. London, England

DMU Research Repository (2014). Retrieved from https://www.dora.dmu.ac.uk/handle/2086/12081

Fischer, M.M., \& Varga, A. (2002). Technological innovation and interfirm cooperation: An exploratory analysis using survey data from manufacturing firms in the metropolitan region of Vienna. International Journal of Technology Management 24(7-8), 724-742.

Ford, P. \& Woudhuysen, J. (2012, August 8-9). The fuzzy front end of product design projects: How universities can manage knowledge transfer and creation. Leading innovation through design. Conference proceedings from international Design Management conference, Boston, USA. Retrieved from https://www.dora.dmu.ac.uk/handle/2086/8407

Ford, P. \& Woudhuysen, J. (2015). Design support for SME's: Publicly funded design support for small and medium manufacturers: how it might be best managed. In Muratovski, G. (Ed.), Design for Business (Volume 3., pp. 62-87). Intellect.

Ford, P. (2016, July 22-29). An intimate approach to the management and integration of design knowledge for small firms. Inflection Point: Design Research Meets Design Practice. Confrence proceedings of $20^{\text {th }}$ DMI: Accademic Conference Boston, USA. Retrieved from https://www.dora.dmu.ac.uk/handle/2086/12833

Hagedoorn, J., \& Duysters, G. (2002). External Sources of innovative capabilities: The preference for strategic alliances or mergers and acquisitions. Journal of management studies, 39(2), 167-188

Hägerstrand, T. (1952). The propagation of innovation waves. Lund Studies in Human Geography, Series B 4, 3-19.

Hargadon, A., \& Sutton, R.I. (1997). Technology brokering and innovation in a product development firm. Administrative Science Quarterly 42, 718-749.

Hewitt-Dundas, N. (2006). Resource and capability constraints to innovation in small and large plants. Small Business Economics, 26(3), 257-277. 
Hoecht, A., \& Trott, P. (2006). Innovation risks of strategic outsourcing. Technovation, 26, 672-681.

Howells, J. (2006). Intermediation and the role of intermediaries in innovation. Science direct research policy, 35, 715-728.

Kaufmann, A., \& Todtling, F. (1999). How effective is innovation support for SMEs? An analysis of the region of Upper Austria. Technovation, 22(3), 147-159.

Latour, B. (1996). On actor-network theory: A few clarifications. Soziale Welt, 47(4), 369-381

Law, J. (2009). Actor network theory and material semiotics. In S. Turner (Ed.), The new Blackwell companion to social theory (pp. 150-174). Blackwell Publishing Ltd.

Lee, S., Park. G., Yoon, B., \& Park, J. (2010). An intermediated network model. Research Policy, 3, 290-300.

Levitt, B., \& March, J.G. (1988). Organizational learning. Annual Review of Sociology 14, 314-340.

Lundvall, B.A. (1992). User-producer relationships, national systems of innovation and internationalization. In Lundvall, B.A. (Ed.), National Systems of Innovation. Pinter, London

Miotti, L., \& Sachwald, F. (2003). Co-operative R\&D: why and with whom? An integrated framework of analysis. Research Policy, 32, 1481-1499.

Narula, R. (2004). R\&D collaboration by SMEs: New opportunities and limitations in the face of globalisation. Technovation 25, 153-161.

Nieto, M. J., \& Santamaria, L. (2007). The importance of diverse collaborative networks for the novelty of product innovation. Science Direct Technovation. 27, 367-377.

Nonaka, I., \& Takeuchi, H. (1995). The Knowledge-Creating Company. New York: Oxford University Press.

Pekkarinen, S., \& Harmaakorpi, V. (2006). Building regional innovation networks: The definition of an age business core process in a regional innovation system. Regional Studies 40(4), 401-413.

Powell, W., Koput, K., \& Smith-Doerr, L. (1996). Interorganisational collaboration and the locus of innovation: Networks of learning in biotechnology. Administrative Science Quarterly, 41(1), 116 146.

Rhodes, C. (2015). Business Statistics : Briefing Paper. House of Lords Library. Retrieved 22 May, 2016, from http://researchbriefings.files.parliament.uk/documents/SN06152/SN06152.pdf

Rogers, E.M. (1962). Diffusion of Innovations. The Free Press, New York.

Roy, R. Potter, S. (1990). Managing design projects in small and medium sized firms. Technology Analysis \& Strategic Management, 2, 321-336. doi: 10.1080/09537329008524018

Sainsbury, Lord. (2005, 22 November). Speech to UK Research base funders' forum plenary conference. Retrieved 25 April, 2016, from

http://webarchive.nationalarchives.gov.uk/+/http://www.dti.gov.uk/ministers/speeches/sainsbu ry221105.html

SBS, (2001). Small and medium-sized enterprise (SME) statistics for the UK. Small Business Service, press release, 21 June.

Smallbone, D., North, D., Roper, \& S. Vickers, I. (2003). Innovation and the use of technology in manufacturing plants and SMEs: An interregional comparison. Environment and Planning C, Government and Policy 21.

Tether, B. (2002). Who co-operates for innovation, and why: An empirical analysis. Research Policy, 31, 947-967.

West, J., Vanhaverbeke, W., \& Chesbrough, H. (2006). Open innovation: A research agenda. In Chesbrough, H., Vanhaverbeke, W.,West, J. (Eds.), Open innovation: Researching a new paradigm. Oxford University Press, NY.

Whitley, R., 2002. Developing innovative competences: the role of institutional frameworks. Industrial and Corporate Change, 11(3), 497-528.

Yaneva, A. (2009). Making the social hold: Toward an actor-network theory of design. Design and Culture, 1(3), 273-288

Zeng, S. X., Xie, X. M., \& Tim, C. M. (2010). Relationship between cooperation networks and innovation performance SME's. Technovation, 30, 181-194. 
About the Authors:

Peter Ford is Professor of Design at De Montfort University UK); he leads the Design Unit, a design research group specialising in assisting SME's to utilise design effectively in their business strategies.

David Terris is a senior design researcher in the De Montfort University Design Unit; he has a particular interest in the new product development process and the creative use of prototyping in the innovation cycle. 